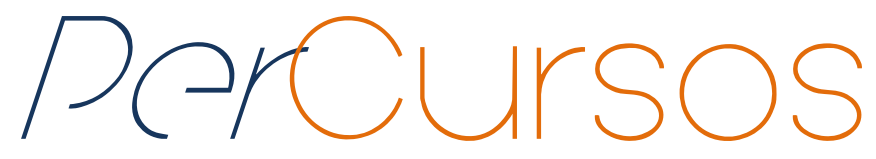

\title{
Capitalismo, território e conflitos: a resistência dos povos e comunidades tradicionais no Brasil ${ }^{1}$
}

\begin{abstract}
Resumo
Esse texto tem como objetivo refletir sobre a territorialização do capital e a capitalização do território na realidade brasileira, numa contraposição à perspectiva difundida na contemporaneidade, em que persiste o discurso de superação da crise e do suposto desenvolvimento do país. O processo de expropriação dos territórios e da natureza tem trazido inúmeros conflitos e impactos aos povos e comunidades tradicionais frente ao modo de produção capitalista. Esse texto é uma revisão bibliográfica sobre o assunto em questão, a partir do materialismo histórico dialético. Conclui-se que, apesar das tensões e dos conflitos existentes entre os capitalistas e os povos e comunidades tradicionais e, da tentativa do capital em desapropriar e negar o acesso à terra - especialmente por meio da violência, da grilagem e da invasão das terras e da exploração da força de trabalho -, existem, por parte dos povos e comunidades tradicionais, a persistência e a resistência em continuar produzindo suas existências em contraposição aos valores e à lógica ora vigentes.
\end{abstract}

Palavras-chave: Capitalismo. Território. Conflitos. Resistência. Agronegócio. Povos e Comunidades Tradicionais.

\section{Anatália Daiane de Oliveira Ramos}

Doutoranda em Educação UFMT. Integrante do Grupo de

Estudos e Pesquisas sobre Trabalho e Educação (GEPTE) UFMT.

anataliadaiane@hotmail.com

\section{Cristiano Apolucena Cabral} Doutorando em Educação -

UFMT. Integrante do GEPTE-

UFMT. Professor efetivo vinculado a Secretaria de Estado de Educação de Mato Grosso (SEDUC-MT). crisprelazia@yahoo.com.br

\section{Eva Emília Freire do Nascimento Azevedo}

Doutoranda em Educação -UFMT. Integrante do GEPTE-UFMT.

Professora do Departamento de Serviço Social na UFMT. evemilia@yahoo.com.br

\section{Edson Caetano}

Doutor em Educação pela UNICAMP e professor do Instituto de Educação (IE) da UFMT. Líder do GEPTE-UFMT. caetanoedson@hotmail.com

\footnotetext{
${ }^{1}$ O presente artigo conta com o apoio da bolsa de demanda social da Coordenação de Aperfeiçoamento de Pessoal de Nível Superior (CAPES) e do Conselho Nacional de Desenvolvimento Científico e Tecnológico (CNPq), por meio do Edital Universal (2014-2017).
} 


\title{
Para citar este artigo:
}

RAMOS, Anatália Daiane de Oliveira; CABRAL, Cristiano Apolucena; AZEVEDO, Eva Emília Freire do Nascimento; CAETANO, Edson. Capitalismo, território e conflitos: a resistência dos povos e comunidades tradicionais no Brasil. Revista PerCursos, Florianópolis, v. 19, n.40, p. 186 - 220, maio/ago. 2018.

\section{DOI: $10.5965 / 1984724619402018186$}

http://dx.doi.org/10.5965/1984724619402018186

\section{Capitalism, territory and conflicts: the resistance of traditional peoples and communities in Brazil}

\begin{abstract}
This text aims to reflect on the territorialization of capital and the capitalization of the territory in the Brazilian reality, in opposition to the diffused perspective in the contemporaneity, in which the discourse of overcoming the crisis and the supposed development of the country persists. The process of expropriation of territories and nature has brought numerous conflicts, impacts of the traditional peoples and communities to the capitalist mode of production. This text deals with a bibliographical revision on the subject in question, from dialectical historical materialism. It is concluded that in spite of tensions and conflicts between capitalists and traditional peoples and communities, and capital's attempt to expropriate and deny access to land - especially through violence, land grabbing and invasion of land and exploitation of the labor force - there is persistence and resistance on the part of traditional people and communities in continuing to produce their existences in contrast to the values and logic that are currently in force.
\end{abstract}

Keywords: Capitalism. Territory. Conflicts. Resistance. Agribusiness. Peoples and Traditional Communities. 


\section{Introdução}

A crise mundial de $2008 \mathrm{fez}$ com que o capitalismo globalizado e nacional reestruturasse suas bases de expropriação de mais-valia, visando aumentar sua taxa de lucro. Em decorrência disso, outras crises vieram: a ambiental, a social e a civilizatória. Sob o pretenso discurso de superação da crise, inúmeras estratégias têm sido utilizadas, dentre elas, o avanço do capital no campo, derrubando matas, extinguindo nascentes e rios, expulsando povos e comunidades tradicionais de seus territórios e transformando a biodiversidade de sementes (floríferas, ornamentais, frutíferas, medicinais e alimentícias) em cenários de monocultura, visando exclusivamente, a riqueza - não para muitos, mas para alguns.

De acordo com o Decreto n. 6040, de 07 de fevereiro de 2017 (BRASIL, 2007), que institui a Política Nacional de Desenvolvimento Sustentável dos Povos e Comunidades Tradicionais, esses são reconhecidos por serem:

grupos culturalmente diferenciados e que se reconhecem como tais, que possuem formas próprias de organização social, que ocupam e usam territórios e recursos naturais como condição para sua reprodução cultural, social, religiosa, ancestral e econômica, utilizando conhecimentos, inovações e práticas gerados e transmitidos pela tradição. $\left(\operatorname{art.} 3^{\circ}, 1\right)$

No âmbito legal reconhecido, na dimensão teórico-conceitual, entendemos os povos e comunidades tradicionais a partir das ideias de Cruz (2012, p. 597-598, grifos do autor):

No campo acadêmico, são trabalhados como uma 'categoria de análise'. Nessa dimensão mais teórico conceitual, os termos 'povos e comunidades tradicionais' buscam uma caracterização socioantropológica de diversos grupos. Estão incluídos nessa categoria povos indígenas, quilombolas, populações agroextrativistas (seringueiros, castanheiros, quebradeiras de coco de babaçu), grupos vinculados aos rios ou ao mar (ribeirinhos, pescadores artesanais, caiçaras, varjeiros, 
jangadeiros, marisqueiros), grupos associados a ecossistemas específicos (pantaneiros, caatingueiros, vazanteiros, geraizeiros, chapadeiros) e grupos associados à agricultura ou à pecuária (faxinais, sertanejos, caipiras, sitiantes, campeiros, fundo de pasto, vaqueiros).

Esses povos e comunidades possuem uma forma de produção da existência que, mesmo dentro do contexto do modo de produção capitalista - que pretende dominar a tudo e a todos -, respeita o ser humano e a natureza. Por isso, são reconhecidos:

a) pela dependência freqüentemente, por uma relação de simbiose entre a natureza, os ciclos naturais e os recursos naturais renováveis com os quais se constrói um modo de vida;

b) pelo conhecimento aprofundado da natureza e de seus ciclos que se reflete na elaboração de estratégias de uso e de manejo dos recursos naturais. Esse conhecimento é transferido por oralidade de geração em geração;

c) pela noção de território ou espaço onde o grupo social se reproduz econômica e socialmente;

d) pela moradia e ocupação desse território por várias gerações, ainda que alguns membros individuais possam ter se deslocado para os centros urbanos e voltado para a terra de seus antepassados [...]. (DIEGUES et al., 2000, p. 21)

Sendo a expropriação dos territórios e da natureza uma das estratégias para ampliar a lógica perversa que caracteriza o modo de produção capitalista, no que diz respeito aos povos e comunidades tradicionais, esse processo tem trazido inúmeros conflitos, impactos e resistências.

Partindo desses primeiros pressupostos, o presente artigo tem como objetivo refletir sobre a territorialização do capital e a capitalização do território na realidade brasileira, numa contraposição à perspectiva desenvolvimentista ${ }^{2}$ que, segundo Sampaio Jr. (2012, p. 674), é “[...] uma arma ideológica das forças econômicas e sociais que, no momento decisivo de cristalização das estruturas da economia e da sociedade burguesa,

\footnotetext{
${ }^{2}$ Segundo Sampaio Júnior (2012, p. 673), "nessa perspectiva, acumulação de capital, avanço das forças produtivas e integração nacional constituem aspectos indissolúveis de um mesmo problema: criar as bases materiais, sociais e culturais de uma sociedade nacional capaz de controlar o sentido, o ritmo e a intensidade do desenvolvimento capitalista".
} 
se batiam pela utopia de um capitalismo domesticado, subordinado aos desígnios da sociedade nacional".

A partir de Kosík (2011), consideramos que o processo de conhecimento é um constante movimento de aproximação e distanciamento, já que a realidade é dinâmica e alterada a cada momento, logo, concreta e histórica. Assim, nos utilizamos do materialismo histórico dialético como método de análise e interpretação da realidade. Trata-se de uma revisão teórica sobre o assunto, em que relacionamos as questões ligadas à terra, ao território, ao capitalismo e, sobretudo, aos povos e comunidades tradicionais.

Com vistas a apontar aspectos que orientam essa discussão, o presente texto está organizado em três partes. Na primeira, refletimos sobre a territorialização do capital e a capitalização do território na realidade brasileira, em que são apontados alguns aspectos, como: apropriação das terras e territórios, os grandes projetos econômicos e de desenvolvimento, as especificidades do agronegócio e sua relação com os povos e comunidades tradicionais.

$\mathrm{Na}$ segunda parte, evidenciamos as lutas pela terra, alguns dados sobre as formas de luta e resistência e a violência no campo, onde os povos e comunidades tradicionais persistem há muito tempo, mesmo em meio às ameaças e forças contrárias no tempo presente. Por fim, construímos algumas considerações possíveis nesse momento histórico, no intuito de disponibilizar elementos/questões para a retomada/continuidade das reflexões, debate e manutenção de resistência à ofensiva constante do capital.

\section{A territorialização do capital e a capitalização do território: reflexões sobre a} realidade brasileira

O capitalismo se organiza por divisões, que são fundamentadas em desigualdades e visam manter a produtividade e a expropriação da força de trabalho. Entre as suas divisões, destacamos a divisão do trabalho local, regional e internacionalmente, talvez 
uma das principais bases para a sua existência e sobrevivência, pois, como afirmava Marx (1988, p. 402) “[...] a relação entre a divisão manufatureira do trabalho e a divisão social do trabalho [é] que constitui o fundamento geral de toda produção de mercadoria".

Na divisão internacional do trabalho, os países situados abaixo da linha do Equador têm uma função relevante para o capital: oferecer matéria-prima e força de trabalho barata aos países localizados acima dessa linha. No Brasil, se confirma a regra para o desenvolvimento (desigual) do capitalismo mundial: oferta de minerais, alimentos e força de trabalho - três mercadorias relevantes ao desenvolvimento industrial e comercial do núcleo orgânico do capital (ARRIGHI, 1997).

A discussão sobre o subdesenvolvimento do Brasil está intrinsecamente ligada à sua dependência e se fundamenta na divisão internacional do trabalho, que nas palavras de Fernandes (2005, p. 341) traz "a extrema concentração social de riqueza, a drenagem para fora de grande parte do excedente econômico nacional, e consequente persistência de formas pré ou subcapitalistas de trabalho e a depressão medular do valor do trabalho assalariado [...]". Mesmo que exista a expropriação para a obtenção do lucro para a burguesia nacional, essa é subordinada à burguesia internacional e à sua ânsia por maiores lucros.

Nessa ânsia, surgem e se aprofundam os grandes projetos econômicos e de “desenvolvimento", entre eles, a mineração, as hidrelétricas, as Pequenas Centrais Hidrelétricas (PCHs) e o agronegócio, os quais apresentam a proposta de modernização, desenvolvimento e industrialização (IANNI, 2004b). Para que essa se efetive, é imprescindível a exploração de recursos naturais e humanos, bem como o controle de território e a mobilização de capital nacional e internacional.

O cumprimento da função desempenhada historicamente pelo Brasil na divisão internacional do trabalho traz diversas consequências, entre elas, as de impactos socioambientais: incentivos fiscais, preços irrisórios dos bens naturais, salários baixos, degradação ambiental, impactos sobre o solo, esgotamentos dos recursos hídricos, atingindo os lençóis freáticos, desestruturação social à população circunvizinha pela instabilidade criada com a mobilização massiva de força de trabalho de outras regiões, 
deformação ambiental e paisagística. Isto é, impacta em toda a dinâmica não somente ecológica ou espacial, mas social, econômica e cultural (ALTIERI, 2012; AMIN; VERGOPOULOS, 1977; LONDRES, 2011; ZIEGLER, 2013).

Essas são algumas das realidades objetivamente condicionadas pelos grandes projetos econômicos e de "desenvolvimento" não contabilizadas ou menosprezadas com a proposta desenvolvimentista (CARVALHO, 2005) de um Estado que pauta sua política econômica em um lucro que é supervalorizado, em detrimento das pautas sociais e ecológicas.

Com a crise mundial de 2008, o capitalismo globalizado e nacional obrigou-se a aprofundar e reorganizar estruturalmente suas bases de expropriação de mais-valia, para aumentar sua taxa de lucro. Junto com essa crise, vieram as crises ambiental e social, construindo bases para outra, a civilizatória. Assim, o que importa para a burguesia nacional e internacional é a maximização do lucro:

[...] o retardamento da Revolução Burguesa, na parte dependente e subdesenvolvida da periferia, adquire assim uma conotação política especial. A burguesia não está só lutando, aí, para consolidar vantagens de classe relativa ou para manter privilégios de classe. Ela luta, simultaneamente, por sua sobrevivência e pela sobrevivência do capitalismo. Isso introduz um elemento político em seus comportamentos de classe que não é típico do capitalismo especialmente nas fases de maturação econômica, socio-cultural e política da dominação burguesa na Europa e nos Estados Unidos. (FERNANDES, 2005, p. 345)

Além de ser dependente e subdesenvolvido, determinado pela divisão internacional do trabalho, o lócus econômico-social em que o capitalismo se assenta no Brasil para a extração de mais-valia, com a intencionalidade de maximizar sua taxa de lucro e a saída da crise, é um lócus tanto pré-capitalista quanto não-capitalista, os quais enquanto categorias são diferentes, mas interligados nas condições objetivas de exploração e expropriação capitalista.

As condições objetivas de sobrevivência a partir do pré-capitalismo se dão pela acumulação primitiva, que é para Marx (1980, p. 830) “apenas o processo histórico que 
dissocia o trabalhador dos meios de produção". No campo, é a expropriação (MARTINS, 1982) - desses meios de produção, da terra, do território - dos povos e comunidades tradicionais.

Quanto à tentativa de sobrevivência do capitalismo pelo lócus não capitalista é, entre outros, direcionado aos mesmos sujeitos sociais (povos e comunidades tradicionais), quando expropria suas mercadorias produzidas em um modelo não capitalista com a terra, com os meios de produção, com a divisão de trabalho e que a intencionalidade da venda é a reprodução da própria existência, e não a produção do lucro e sua maximização (CARVALHO, 2005; MARTINS, 1986). O capital necessita expropriar a força de trabalho e os produtos destes sujeitos sociais para a manutenção de sua existência. Nas palavras de Mandel (1982, p. 29), “o movimento efetivo do capital manifestamente começa a partir de relações não capitalistas e prossegue dentro do quadro de referência de uma troca constante, exploradora, metabólica, com esse meio não capitalista”.

O desenvolvimento desigual, combinado nacional e internacionalmente, amparam essa lógica de obtenção de lucro. Por isso, os grandes projetos buscam sustentar as demandas do capital autóctone e internacional por minerais, grãos, carnes, madeiras, energia, água e terra em detrimento às demandas pertinentes da população marginalizada, explorada e expropriada.

Sem retirar a relevância de outros grandes projetos, o agronegócio se tornou, depois da Revolução Verde, um dos principais motores do capitalismo brasileiro, adquirindo papel central no cenário econômico mundial. Segundo Carvalho (2005, p. 198),

Como agronegócio burguês compreende-se o conjunto de empresas capitalistas que direta ou indiretamente estão relacionadas com os processos de produção, de beneficiamento, de industrialização e de comercialização de produtos e subprodutos de origem agrícola, pecuária, florestal e agroextrativista, e que são comercializadas com o maior ou menor grau de beneficiamento predominantemente na Bolsa de Mercadorias e Futuros (BM\&F). 
A territorialização do capital é efetivada pelo agronegócio. Segundo Moreira (2007, p. 32), “a territorialização do capital é, assim, um dos elementos da sujeição da força de trabalho agrícola ao capital”. Desta forma, o capital se apropria - enquanto modo de produção - do campo, rompendo e mantendo (de acordo com suas necessidades e interesses) o modo de produção não capitalista.

Com o agronegócio no campo, a indústria se efetiva nesse espaço: “ora, a procura de produtos agrícolas [que] não é senão a oferta dos produtos industriais" (AMIN; VERGOPOULOS, 1977, p. 88). Na industrialização, artificializa-se a natureza; na artificialização, dá-se um preço e mercantilizam-se recursos naturais como água, terra, alimentos. Neste sentido, o capitalismo também vai ao campo.

Com a presença da indústria no campo, chega-se à divisão entre a força de trabalho e os meios de produção e uma nova divisão do trabalho. Além disso, se consolidam o monopólio sobre a terra, o capital, os produtos, a comercialização e os meios de produção.

O monopólio de classe sobre a terra e o monopólio de classe sobre o capital - as ferramentas, as matérias-primas, o dinheiro dos salários - são imprescindíveis no capitalismo para subjugar o trabalho dos trabalhadores, para fazer com que estes trabalhem para o capital [...]. (MARTINS, 1986, p. 165)

Com a monopolização, homogeneízam-se as práticas produtivas e sobrepõe-se uma só forma de produzir: a capitalista. Desta maneira, os modos de produzir não capitalistas ou são invisibilizados pelos meios de comunicação por causa de sua relevância à sustentabilidade sócio-ecológica em suas maneiras de produzir e reproduzir a vida material e imaterial ou são exterminados (mortos), tal como acontece com os povos e comunidades tradicionais. Além de pretender a homogeneização das práticas produtivas, homogeneízam-se os produtos do campo, simplificando-os aos padrões de produção e de consumo. 
De fato, as paisagens agrícolas do mundo são destinadas ao plantio de apenas 12 espécies, 23 espécies de hortaliças e 35 espécies de frutas e nozes. Isso significa que não mais que 70 espécies ocupam aproximadamente 1,44 bilhão de hectares de terras hoje cultivadas no mundo. (ALTIERI, 2012, p. 24)

A padronização dos produtos industriais determina e condiciona a uma padronização dos produtos da natureza, com o intuito de satisfazer às demandas comerciais de massa. Desta forma, a riqueza e diversidade dos produtos dos povos e comunidades tradicionais tornam-se anacrônicas e obsoletas.

$\mathrm{Na}$ intencionalidade dessa padronização das mercadorias produzidas pelas indústrias e, na sua posterior comercialização, algumas mudanças são determinantes, entre elas, as inovações físico-químicas, as quais "modificam as condições naturais do solo, elevando a produtividade do trabalho aplicado a esse meio de produção básico" (DELGADO, 1985, p. 92) e as inovações biológicas, "que afetam principalmente a velocidade da produção do capital adiantado no processo produtivo, através da redução do período de trabalho e da potencialização das inovações mecânicas e físico-químicas" (DELGADO, 1985, p. 92).

Na mesma lógica da territorialização do capital, ou seja, da transformação do campo pelo capital - sofrendo os impactos ecológicos, sociais, culturais e econômicos -, a monocultura se faz necessária e determinante. No Brasil, produtos como soja, algodão, milho, cana-de-açúcar, eucalipto, cacau, café e laranja predominam nas áreas cultivadas. Em se tratando da produção mundial, não existe diferença, pois "91\% dos 1,5 bilhão de hectares de terras cultivadas estão principalmente sob monoculturas de trigo, arroz, milho, algodão e soja" (ALTIERI, 2012, p. 26).

A mecanização, as inovações físico-químico-biológicas e seu melhoramento genético, os agrotóxicos e a industrialização de fertilizantes e adubos facilitam a possibilidade dessa monocultura - embora seus impactos não sejam computados.

Uma das consequências intencionais desse processo de territorialização do capital é, tal como em outras indústrias, o oligopólio das sementes e de sua produção. De acordo com Ziegler (2013, p. 152) 


\begin{abstract}
Apenas dez sociedades - entre as quais a Avantis, a Monsanto, a Pionner e a Syngente ${ }^{3}$ - controlam um terço do mercado mundial de sementes, cujo volume é estimando em 23 bilhões de dólares por ano, e $80 \%$ do mercado mundial de pesticidas, estimado em 28 bilhões de dólares. Dez outras sociedades, entre as quais a Cargill, controlam $37 \%$ das receitas das 100 maiores sociedades fabricantes de produtos alimentícios e de bebidas. E seis empresas controlavam $77 \%$ do mercado de adubos: Bayer, Syngenta, Basf, Cargill, Dupont e Monsanto.
\end{abstract}

Os diversos momentos da produção e seus setores são oligopolizados: sementes, agrotóxicos utilizados para a maximização da produção, produtos finais e adubos. Assim, pela oligopolização, os preços são determinados e impostos por essas transnacionais, todas presentes no Brasil. Os preços podem ser elevados - para a obtenção de lucros ou reduzidos - para a eliminação dos concorrentes. Movimentos estes fundantes à natureza comercial do capital monopolista e oligopolista. As transnacionais limitam os empresários do agronegócio e os pequenos produtores (ALTIERI, 2012) sobre quais sementes plantar, quando plantar, a quem vender, onde comercializar e quem deve plantar - enfraquecendo o poder de comunidades e povos tradicionais sobre suas sementes.

Isso acontece também em relação aos agrotóxicos. Segundo Londres (2011, p. 19), “entre 2001 e 2008 a venda de venenos agrícolas no país saltou de pouco mais de US\$ 2 bilhões para mais de US\$ 7 bilhões, quando alcançamos a triste posição de maiores consumidores mundial de venenos" - valores esses concentrados nas mãos de pouquíssimas transnacionais. Estes venenos atacam diversas vidas naturais para constituir uma "qualidade" artificial e perigosa. Entre esses, estão os fungicidas, os herbicidas, os inseticidas, os acaricidas e os formicidas.

Assim, a agricultura sob a determinação do capitalismo, ou melhor, sob a territorialização do capital, se monopolizou. Desta forma, o capital subjuga a agricultura a seu modo de produção e reprodução metabólico, cuja intencionalidade é o lucro e sua maximização.

\footnotetext{
${ }^{3}$ Multinacionais que produzem agrotóxicos em larga escala e tem o poder político e econômico de condicionar os Estados a consumirem seus produtos.
} 
Uma dessas subjugações é tornar os produtos agrícolas commodities, os quais têm como objetivo a produção, o melhoramento, a industrialização e a exportação. No Brasil, os produtos de exportação são: milho, soja em farelos e óleo, algodão, cacau, açúcar e etanol, café, suco de laranja e carne bovina. Tais produtos são priorizados pelo agronegócio, pois, na divisão internacional do trabalho, são essas as demandas dos países e suas transnacionais, detentoras das decisões do quê e como produzir.

Outro comportamento característico do país é o entrelaçamento de seus produtos agrícolas à Bolsa de Mercados e de Futuros (BM\&F). Essas bolsas têm um poder determinante sobre os preços de commodities mundial e, por fim, os monopólios. Esses controlam as terras, o processo produtivo, os produtos e suas comercializações, subordinando não somente o modo de produção capitalista, mas dominando ou tentando dominar o modo de produção não capitalista ${ }^{4}$ de povos e comunidades tradicionais, já que o controle e a subordinação são essenciais para a reprodução do capital (DELGADO, 1985).

A partir da consolidação desse sistema e entre todos os produtos possíveis de se produzir no campo, os alimentos se tornam mercadorias e tal como qualquer outra, seu valor de uso essencial fundamenta-se como valor de troca. Essa mercantilização contribui para a limitação e fragilização da segurança alimentar, pois o acesso e a disponibilidade de alimentos à população tornam-se escassos, considerando que a prioridade não é o suprimento da fome ${ }^{5}$, mas os possíveis lucros a serem obtidos. Assim, se há possibilidade de obter lucros com o álcool, com algodão ou com soja para exportação, se utilizarão todos os monopólios voltados a esses produtos e não à produção de arroz, feijão e trigo, por exemplo.

Além da insegurança alimentar, pode-se vislumbrar uma desestabilização e crise na soberania alimentar. Com a monocultura, artificialização e oligopólios das sementes, o

\footnotetext{
4 "A produção capitalista de relações não-capitalistas de produção expressa não apenas uma forma de reprodução ampliada do capital, mas também a reprodução ampliada das contradições do capitalismo o movimento contraditório não só de subordinação de relações antagônicas e subordinadas nãocapitalistas" (MARTINS, 1981, p. 21).

${ }^{5}$ Conforme relatório da FAO, IFAD, UNICEF, WFP and WHO (2018), o número de pessoas que sofrem com a fome no mundo aumentou de 777 milhões em 2015, para 815 milhões de pessoas em 2016. Conforme dados do IBGE (2017), no Brasil, estão abaixo da linha de pobreza mais de 52 milhões de pessoas, ou seja, $25,4 \%$ da população.
} 
direito de manter e desenvolver as próprias sementes pelos povos e comunidades tradicionais é colocado em xeque, reduzindo, dessa forma, as diversidades de sementes e, consequentemente, as diversidades culturais.

A transnacionalização dos produtos agropecuários acirra a desestabilização na segurança e na soberania alimentar - e com elas, a fome. Mandel (1990, p. 115) aponta como exemplo que: "a fome de 1973/74 foi em grande parte pré-fabricada pela política deliberada de sustentação de preços de uma redução artificial das áreas plantadas e da produção, ou seja, através da lógica infernal da economia de mercado".

A fome não é uma condição natural, mas uma determinação e decisão política e econômica, uma vez que o que domina a sociedade mundial e brasileira não é a vida humana, mas o capital, que a tudo tenta dominar: a produção, os meios para que ela aconteça, os produtos, a força de trabalho, a comercialização, os preços, o que pode ou não consumir etc.

\begin{abstract}
A tendência do capital é dominar tudo, subordinar todos os setores e ramos da produção e, pouco a pouco, ele o faz. Só não poderá fazê-lo se adiante dele se levantar um obstáculo que o impeça de circular e dominar livremente, que o impeça de ir adiante a terra é esse obstáculo. Sem a licença do proprietário da terra, o capital não poderá subordinar a agricultura. Como o capital tudo transforma em mercadoria, também a terra passa por essa transformação, adquire preço, pode ser comprada e vendida, pode ser alugada. A licença para a exploração da terra depende, pois de um pagamento ao seu proprietário. Esse pagamento é a renda da terra. (MARTINS, 1986, p. 160-161)
\end{abstract}

Para que a territorialização se efetive, o acesso à terra é fundamental para o capital. Sem a terra, o capital industrial, comercial e financeiro não se unifica ao agronegócio. Nesse sentido, o acesso à terra se dá por meio da compra, do aluguel, da desapropriação de assentados, posseiros e povos e comunidades tradicionais ou, por fim, da grilagem ${ }^{6}$ de terras públicas.

\footnotetext{
${ }^{6}$ Segundo Carvalho (1980), grileiro é uma denominação produzida pelo povo para se referir às pessoas que se apossam de uma terra que não é sua e nada plantam nela, ou seja, “criam grilos”. Especulam e lucram da terra, por meio da falsificação de títulos e da corrupção de escrivães e cartórios, obtendo grandes
} 
Quando há compra ou aluguel de terras, o capitalista paga a renda por ela.

Com a generalização do mercado de terras, a parte do capital social que se encontra imobilizado em terras vai funcionar como equivalente de capital; em nossa perspectiva, é capital territorializado. Apresenta uma rigidez de localização, um limite à sua mobilidade, mas apresenta também uma potência múltipla devido à fertilidade. (MOREIRA, 2007, p. 38-39)

Ao pagar pela utilização da terra, parte do capital converte-se em renda, imobilizando assim, o capital que poderia ser gasto na criação de mais capital. Essa imobilidade do capital em renda torna-se improdutiva e irracional em um sistema em crise. Por isso que há nos últimos anos ataques violentos às terras públicas, de assentados, de posseiros e de povos e comunidades tradicionais. Essa tentativa de expropriação é a saída lógica ao não pagamento da renda fundiária.

Contudo, há duas realidades de acesso à terra: através da compra ou através da expropriação; já que, de uma maneira ou de outra, a terra é lócus da produção, bem como reserva de valor. Conforme Martins (1986, p. 166, grifo do autor),

Mesmo que o proprietário não ponha a sua terra para trabalhar, ainda assim ela the dará direito de se apropriar de uma parte de riqueza socialmente produzida. Quando o proprietário diz que a sua terra está 'valorizando' ele denuncia exatamente o caráter irracional da propriedade fundiária: como pode a terra valorizar-se se ela permanece improdutiva, se ela não incorpora trabalho, se não devolve produtos? Isso só pode acontecer se o trabalho que valoriza a propriedade não precisa ser feito necessariamente na propriedade. À medida que a terra já trabalhada é insuficiente para atender essa necessidade, o valor da terra cresce - a sociedade estará disposta a repartir com os proprietários uma parte crescente da sua riqueza para os alimentos possam ser produzidos.

A terra é valorizada, mesmo que em dado momento nada esteja sendo produzindo nela. O capital se aproveita dos benefícios da concentração monopolizada das terras e 
das demandas crescentes de seus produtos à população. Isto é, a marginalização do acesso à terra de alguns e a limitação da oferta de alimentos provocam a valorização e lucros de outros. Além disso, a terra se posiciona na dinâmica do capital financeiroespeculativo. Seus valores sofrem as tendências de determinações futuras: descobertas de mineração, construção de rodovias etc (AMIN; VERGOPOULOS, 1977).

São essas condições objetivas da realidade capitalista do campo que fortalecem a necessidade de acesso à terra, de uma maneira ou de outra. São essas mesmas condições que consolidam a relevância da concentração de terras. Nesse movimento crescente da concentração da terra, vê-se a relevância do capital territorializado, tal como do território capitalizado. É a terra que mobiliza o capital industrial, comercial e financeiro, reproduzindo o sistema metabólico do capital. Assim,

Criam-se estímulos e favores fiscais e creditícios para a formação, expansão, crescimento, aperfeiçoamento ou modernização da empresa agrícola, pecuária, extrativista ou agroindustrial. Tanto a agricultura intensiva como a extensiva receberam favores e estímulos fiscais e creditícios, econômicos, e políticos de bancos, superintendências e fundos pertencentes ao Estado, e postos à disposição da empresa nacional e estrangeira. (IANNI, 1979, p. 47)

A circulação de capitais pelo sistema financeiro tornou-se presente na agropecuária, tanto em todo o processo de produção, circulação e consumo quanto na capitalização do território. Nesse sentido, o Estado é uma peça fundamental a todo esse processo, seja como provedor de capital, criando leis que facilitem a obtenção de lucros e a maximização na exploração da força de trabalho e na industrialização da natureza, como na administração das lutas entre capital-trabalho, capital-natureza, capital-cultura, capital-terra/território (IANNI, 2004b).

Ianni (2004b, p. 19-20) afirma que "com o evoluir desse processo econômico-social e político de amplas proporções, o Estado se configura como instrumento decisivo de coordenação e ação em todas as esferas da economia", uma vez que se utiliza de um complexo mecanismo de estímulo, compensação, financiamento, conexões intersetoriais e facilitação na integração entre os capitais agrários, industriais, comerciais e bancários. 
Nesse momento, parece-nos primordial o seguinte questionamento: quais as consequências dessa territorialização do capital e capitalização do território tanto à natureza quanto aos povos e comunidades tradicionais? Segundo Carvalho (2005, p. 107), o Brasil é "o país detentor da maior parcela da biodiversidade mundial: cerca de $17 \%$ do total”, e só no cerrado brasileiro há uma estimativa da existência de mais de "600 espécies de árvores" (CARVALHO, 2005, p. 105).

Logo, o impacto à natureza e à sua biodiversidade é visível: as novas e fortes pragas, consequência da enorme utilização de agrotóxicos; a diminuição de rios, córregos e lençóis freáticos; a homogeneização da paisagem, da fauna e flora, de alimentos; o assoreamento de solos; o envenenamento de plantas, solos, águas, alimentos e pessoaspara citar apenas alguns (ALTIERI, 2012).

Além dos impactos ambientais, existem os impactos aos povos e comunidades tradicionais, em sua produção material e imaterial da vida, ou seja, da produção de sua existência, no que tange à terra e ao território, sobre os meios de produção e produtos, sobre a divisão e jornada de trabalho, no respeito e cuidado à natureza, na solidariedade e coletividade, na ressignificação do valor de uso e de troca.

Os impactos aos povos e comunidades tradicionais podem ser analisados desde 0 período da invasão - nosso primeiro golpe, conforme expressa Krenak (2016) ${ }^{7}$. Segundo ele, de forma abrupta, a expropriação da terra dos que aqui estavam e a prática da propriedade privada, transformaram - e ainda transformam - os territórios com a construção de infraestruturas que, cada vez mais, atravessam as florestas, o cerrado, o pantanal, cortando e alterando assim, as paisagens naturais e expulsando os povos de seus territórios originários.

Nesse sentido, podemos observar que, apenas deixar os povos e as comunidades tradicionais à margem não é mais suficiente, é preciso atacá-los, é preciso tomar seus territórios, pois como o capital precisa cada vez mais de terra, de água, de minério, ele se apropria e altera tudo, na sua compulsão pelo lucro (KRENAK, 2016).

\footnotetext{
7 Em Conferência intitulada “Estado, Capital e Territórios Tradicionais", realizada no “IV Colóquio Internacional Povos e Comunidades Tradicionais: Estado, Capital e Territórios Tradicionais: dinâmicas territoriais em disputa". Montes Claros: Unimontes, 2016.
} 
Na medida em que os povos e comunidades tradicionais vivenciam a produção da existência de maneira distinta e, por vezes, em oposição aos preceitos capitalistas - de desenvolvimento, modernização produção em massa etc. -, esse sistema busca eliminálos.

Ainda assim, apesar de todas as intencionalidades do capital, esses povos com as características $^{8}$ que lhes são peculiares - a forma como se relacionam com a natureza, o cuidado e respeito ao território (a maneira como moram e ocupam esses espaços), a forma como produzem a existência, sem exploração do trabalho de uns sobre os outros em meio a todos os cenários contrários, os vivenciam e resistem, conforme trataremos a seguir.

\section{Conflitos e resistência dos povos e comunidades tradicionais: uma questão}

\section{contemporânea}

A transformação da terra em mercadoria baseada na lógica capitalista adotada aqui no Brasil provocou alterações sociais, econômicas e políticas que afetam diretamente os povos e comunidades tradicionais. Essa perspectiva tem cotidianamente intensificado a luta pela terra no nosso país.

O crescimento econômico tem gerado aumento na procura de terras consideradas adequadas para plantações e pastos, bem como, o aumento da luta pelas terras devolutas, invadidas, griladas ou ocupadas. Desta forma, também aumentam as tensões e os conflitos entre os povos e comunidades tradicionais e o modo de produção capitalista, já que suas lógicas orientam formas antagônicas de produção da existência.

Segundo Martins (1986, p. 109),

Índios e posseiros ${ }^{9}$ estão sendo alcançados por processos econômicos e políticos que, no fundo, não são diferentes para um e outro. Tanto a terra

\footnotetext{
${ }^{8}$ Conforme expressam Diegues et al (2000).

${ }^{9}$ Para Martins (1986), posseiro é o lavrador pobre que trabalha na terra, que reserva parte de sua produção para o seu sustento e de sua família e que vende os excedentes no mercado com o intuito de adquirir
} 
do índio quanto a terra do posseiro entram hoje abertamente nos cálculos dos grandes grupos econômicos e do Estado, que os estimula e ampara no avanço acelerado sobre esses territórios.

Embora lanni (1978) estivesse relatando e analisando a história de luta pela apropriação e o uso de terra no município de Conceição do Araguaia, estado do Pará ${ }^{10}$ período de 1897 a 1977 -, a reflexão sobre a transformação da terra em mercadoria que o autor constrói é muito pertinente para refletirmos sobre o nosso contexto nacional e contemporâneo. Segundo o autor,

Em pouco tempo, também a terra passa a ser mercadoria, ganha preço; isto é, apropriada de modo privado e sob nenhuma outra forma. A terra passa a ser objeto e meio de produção de valores de troca. É inserida nas relações capitalistas de produção como um elemento das condições de produção controladas pela empresa privada. Pouco a pouco, ou de súbito, conforme o caso, a terra deixa de ser apenas, ou principalmente, objeto e meio de produção de valores de uso. O poder estatal aparece, de forma cada vez mais ostensiva e permanente, como um poder maior destinado a favorecer e a acelerar o processo de privatização da terra, nos moldes exigidos pela empresa privada de grande porte, segundo a lógica da acumulação capitalista.

Parece ter havido uma súbita metamorfose da terra. A terra, que parecia larga, farta, sem fim, de súbito ganha outra fisionomia social. Ganha outra dimensão histórica. Antes, parecia um elemento secundário, ou mesmo irrelevante, pois que o principal era extrair drogas do sertão, a borracha, a castanha, o babaçu. A delimitação da «propriedade» era apenas um modo de defender as árvores, animais, aves, peixes, para a produção de autoconsumo dos produtores, ou para o comércio. (IANNI, 1978, p. 154, grifo do autor)

Ianni (1978, p. 154) afirma que as pessoas mudaram por causa da terra e o que garantia a sua propriedade não era mais sua ocupação, posse, moradia, roças, criação de animais, conhecimento no lugar, saberes e vizinhança. Agora era indispensável "[...] ter papel, documento, título, prova, escritura, para que a propriedade fosse propriedade".

"[...] remédios, sal, querosene, às vezes roupa e mais uma ou outra coisa necessária à casa ou ao trabalho" (p. 104).

${ }^{10}$ De acordo com Martins (1986), a região do sul do Pará, onde está localizado o município de Conceição do Araguaia, é "[...] uma das regiões de mais graves conflitos de terra no Brasil de hoje [...]" (p. 105). 
A terra, na perspectiva dos povos e comunidades tradicionais não está relacionada apenas à delimitação espacial, mas também ao espaço de liberdade, à garantia da sobrevivência física coletiva por meio da produção de alimentos, caça, pesca e criação de animais, à dimensão simbólica, identitária e afetiva de mulheres e homens pertencentes a esses povos e comunidades, à relação diferenciada e respeitosa com a natureza, à construção do abrigo etc. (ARESI, 2008; SILVA; SATO, 2012), extrapolando, assim, para o conceito de território. Mas, para o modo de produção capitalista, deve ser explorada o máximo possível. Assim, existem interesses diferentes e antagônicos, logo, luta de classes.

Com o intuito de maximizar o lucro, as pessoas que defendem o modo de produção capitalista - empresárias, fazendeiras, comerciantes, mineradoras, agropecuaristas etc. - defendem a exploração, a grilagem e invasão da terra, o crescimento contínuo da produção e do consumo de mercadorias, a padronização dos produtos, a concentração das redes de coletas e comercialização, a exploração da força de trabalho, o acesso e aumento de financiamentos e créditos destinados ao agronegócio, à mineração, às hidrelétricas etc.

\begin{abstract}
O Brasil, um dos países protagonistas do novo cenário de transformação geopolítica mundial, tem buscado a qualquer custo seu desenvolvimento econômico. Com isso, a demanda por água, energia, minérios, combustíveis e espaços territoriais tem se tornado cada vez mais crescente, o que pode ser constatado por meio do aumento de instalação de grandes usinas hidrelétricas, hidrovias, ferrovias, aberturas e pavimentações de estradas, avanço da fronteira agrícola e outros grandes projetos. Contudo, todo esse processo tem sido conduzido, muitas vezes, sem planejamento e/ou sem respeito às legislações vigentes, desconsiderando as consequências dessas ações ao ambiente e às sociedades de maneira geral. (SILVA; SATO, 2012, p. 1)
\end{abstract}

Enfim, o discurso que enaltece a lógica capitalista implica defender conscientemente ou não - a expulsão e a eliminação dos povos e comunidades tradicionais, considerados entraves ao "desenvolvimento do país", uma vez que não se encaixam nos padrões de modernidade e progresso defendidos pelo sistema capitalista, buscam a conservação das diversidades biológicas e das diferenças culturais, lutam pelo 
território e pela manutenção da biodiversidade e dos ecossistemas nele presentes, negam o desmatamento etc. (SILVA; SATO, 2012; SILVA, 2007; SILVA, 2011).

$\mathrm{Na}$ Amazônia brasileira, por exemplo, os fazendeiros, que vivem de renda e especulação da terra, da extração de madeiras e criação de gado, e os mineradores da região são os principais sujeitos sociais que se organizam - inclusive com contratação de pistoleiros ou policiais - para expulsar os povos e comunidades tradicionais dos territórios em que vivem, já que são espaços de extração de riquezas (SANTOS, 1993).

Nesses e em outros espaços também se instauram os empreendimentos econômicos (empresas imobiliárias, ferroviárias, comerciais, bancárias etc.), que loteiam vastas extensões de terras, produzem e transportam mercadorias, compram, vendem e financiam a produção - no caso das plantações de soja, milho e algodão baseadas, geralmente, em quantidades abusivas de agrotóxicos - e o comércio (MARTINS, 1975).

Existem os povos e as comunidades tradicionais que têm suas terras invadidas por fazendeiros (SILVA; SATO, 2010), bem como, aquelas que são perseguidas pelos fazendeiros que temem perder a terra e não serem ressarcidos pelo uso das terras indevidamente ocupadas, como acontece com o complexo de Mata Cavalo ${ }^{11}$ em Nossa Senhora do Livramento, Mato Grosso (SIMIONE, 2008).

Em alguns estados, como é o caso de Mato Grosso, a terra é comprada por empresários do agronegócio que buscam industrializar e padronizar a produção, aumentando a produtividade, diminuindo os custos e maximizando o lucro e, por isso, contam com a forte presença dos capitais comerciais e financeiros. Neste sentido, segundo Silva (2012, p. 71), em Mato Grosso, o movimento a favor do agronegócio

[...] reforçou a estrutura agrária dominante em latifúndios, que, além das medidas jurídicas que os favoreceram, contaram ainda com um vasto conjunto de incentivos financeiros e fiscais que garantiu a prosperidade da agropecuária em MT. Vários programas abonaram (e ainda abonam) os grandes produtores rurais deste Estado, desde assistências técnicas,

\footnotetext{
11 "[...] o complexo Mata Cavalo é uma comunidade negra rural formada por seis comunidades próximas de quilombos, cujas terras atuais foram adquiridas por doações ou compra pelos antigos ex-escravos" (SIMIONE, 2008, p. 19-20).
} 
financiamentos para agrotóxicos potentes e tecnologias de última geração (maquinários e transgênicos), que somados às boas condições do solo, relevo e clima cravaram em MT a monocultura, garantiram a concentração de terras e acirraram ainda mais os conflitos socioambientais.

Vale dizer que, para se ter acesso à renda fundiária, financiamentos, créditos, incentivos fiscais, isenção de impostos, expropriação de mais valia etc., os fazendeiros e empresários do agronegócio acabam atacando os povos e comunidades tradicionais. Desta forma, Silva (2012) denuncia que, em Mato Grosso, à expansão do agronegócio vinculam-se os altos índices de violência no campo, quer seja em relação à reforma agrária, quer seja em relação à questão indígena.

De acordo com Silva e Sato (2012, p. 21), em Mato Grosso

\begin{abstract}
As narrativas dos grupos sociais centraram-se fortemente nos embates encarados pelos diversos grupos que disputam porções do território mato-grossense com o setor do agronegócio, em função da dominação/concentração territorial, que implicam em outras disputas como o acesso a água e a outros bens naturais. Indubitavelmente, em MT, são nas disputas pela terra que se estabelecem as situações mais conflitantes, frutos do modelo concentrador agrário-agrícola em desenvolvimento no Brasil e no Estado.
\end{abstract}

Neste sentido, a violência é uma "triste garantia" aos povos e comunidades tradicionais, já que produzem suas existências em contraposição aos valores e lógica do modo de produção capitalista. Além de rejeitar se tornarem proletários ou burgueses, os povos e comunidades tradicionais se negam a suprir as demandas do Mercado, a gerar renda fundiária e mais valia e, por fim, não se adequam às demandas da produção da existência determinada pelo capital.

Essas negações e contraposição às determinações do capital, materializadas em diferentes tipos de resistência, provocam tensões e conflitos de classe. Do lado do capital, os conflitos são alicerçados na necessidade de expandir a concentração e centralização da terra, do poder, do lucro, dos minérios, das vegetações brasileiras, da água, dos alimentos etc. Por isso, lança mão à criminalização, à violência física, 
psicológica, moral, cultural e simbólica, ao desmatamento, às queimadas, às ameaças de morte, às invasões e grilagens de terra, à falta de demarcação dos territórios indígenas e quilombolas, ao trabalho escravo, à exploração da natureza, ao assoreamento dos rios etc. (SILVA; SATO, 2012).

lanni (1978, p. 207) elenca algumas formas de violência ocorridas num município do estado do Pará:

As pressões, as ameaças, a entrada do gado nas roças, a queima das casas, a presença do oficial de justiça representando a lei, ou da polícia representando a violência institucionalizada, muitos são os ingredientes da violência que passou a povoar o cotidiano do posseiro, em Itaipavas, São Geraldo, Floresta, Rio Maria e outros povoados e lugares do município de Conceição do Araguaia.

As tensões, os conflitos - políticos, sociais, culturais, territoriais, ambientais etc. e as violências - física, psicológica, simbólica e moral realizadas pelo governo, mídia, empresários, fazendeiros etc. - contra os povos e as comunidades tradicionais não datam de hoje, pelo contrário, marcam a triste história brasileira desde a sua invasão.

Entre os episódios das tensões, dos conflitos e das violências contra os povos e comunidades tradicionais datados no século XX, estão aqueles denunciados por Carvalho (1980) e denominados pelo autor de "Guerra na Amazônia". Entre as denúncias feitas, está a da comunidade Divino Pai Eterno, no povoado de Barreira do Campo, município de Santana, estado do Pará. A comunidade, localizada próxima às fazendas de Manah, criava bovinos para a produção de carne para a exportação. Na época, a comunidade enfrentava havia três anos, uma luta aberta e armada; os pistoleiros de Manah e os ataques da polícia. O líder da comunidade, Antônio Nunes Cabral, relatou:

Para escrever essa nossa história tem que ir lá ver de perto. Os pistoleiros estão lá, rodeando direto, tocaiando nas matas, atirando nas casas de noite, fazendo tudo quanto é barbaridade. Nós estamos lá nessa terra há mais de dezesseis anos, temos o direito que mesmo os doutores reconhecem, mas que a Manah não quer respeitar. (CARVALHO, 1980, p. 11) 
Segundo o autor, devido a essa luta, as pessoas da comunidade aprenderam a jamais andarem sozinhas e desarmadas. Visitar um bananal, ir trabalhar nas roças, ir às matas e/ou à cidade, dormir e outras atividades cotidianas eram feitas coletivamente e com homens armados. Embora armados, a lógica das pessoas da comunidade era distinta dos pistoleiros e da polícia. Enquanto na comunidade, segundo o Sr. Antônio “[...] a gente não quer mesmo matar ninguém, só espantar pra eles deixar a gente em paz" (CARVALHO, 1980, p. 13), os pistoleiros e a polícia possuíam a intenção de matar e destruir a comunidade.

Tomando como referência o relato de Sr. Antônio e a citação a seguir, percebemos que, ao descrever e problematizar sobre a Comuna de Paris, Marx (2011) nos ajuda a refletir acerca da violência empregada pela classe dominante em favor dos seus privilégios e que, mesmo frente ao inimigo e num contexto de guerra, as trabalhadoras e os trabalhadores não se portam com a mesma violência, embora se utilizem das mesmas armas que seus inimigos.

Quando Thiers bombardeou Paris durante seis semanas, sob o pretexto de que só queria pôr fogo nas casas habitadas, foi ele incendiário? $\mathrm{Na}$ guerra, o fogo é uma arma tão legítima quanto qualquer outra. Os edifícios ocupados pelo inimigo são bombardeados a fim de incendiá-los. Se seus ocupantes são forçados a se retirar, eles próprios ateiam fogo para prevenir que os agressores façam uso dos prédios. [...]. Mas na guerra dos escravizados contra os escravocratas, a única guerra justificável da história, esse argumento não tem validade, de modo algum! A Comuna usou do fogo estritamente como um meio de defesa. Utilizou-o para bloquear às tropas de Versalhes o acesso àquelas amplas e retas avenidas que Haussmann havia aberto expressamente para que nelas pudesse se deslocar o fogo da artilharia; empregou-o para cobrir sua retirada, do mesmo modo que os versalheses, em seu avanço, usaram suas granadas que destruíram pelo menos tantos edifícios como o fogo da Comuna. [...]. E os defensores recorreram ao fogo apenas quando as tropas versalhesas já haviam dado início ao assassinato em massa de prisioneiros. [...]. A Comuna sabia que seus inimigos não se importavam com as vidas do povo de Paris, mas se importavam muito com os edifícios parisienses que lhes pertenciam. E Thiers, por outro lado, Ihes havia advertido que seria implacável em sua vingança. [...]. Se os atos dos trabalhadores de Paris foram de vandalismo, era o 
vandalismo da defesa em desespero, não o vandalismo do triunfo [...]. (MARX, 2011, p. 75)

Embora a análise e a reflexão feitas por Marx (2011) estejam relacionadas a um contexto urbano e a uma situação específica, e no presente artigo nos debrucemos sobre campo brasileiro, julgamos que a referida citação nos permite refletir e problematizar que a violência empregada pelos dominantes - empresários do agronegócio, grandes produtores rurais, fazendeiros, pecuaristas e os demais grupos pertencentes a essa classe - é maior e com finalidade diferente daquela empregada pelos “dominados”. Do lado dos dominantes, emprega-se todo tipo de violência para a manutenção de seus privilégios e a maximização dos seus lucros e, do lado dos "dominados", a violência é utilizada para "barrar" o avanço dos dominantes, bem como a favor de sua própria existência.

Martins (1986) contribui com nossa discussão através de suas denúncias e análises acerca da grande violência que marca os conflitos existentes na Amazônia Legal brasileira. Segundo o autor,

No período de 1971 a 1976, um em cada dois conflitos noticiados teve vítimas (morto e feridos), sendo que mais de $50 \%$ correspondem aos casos de morte. O maior número de mortos do que de feridos indica o grau de violência atingido na disputa pela terra. São considerados vítimas, nesses casos, unicamente os mortos e feridos. Entretanto, seria necessário incluir entre elas os posseiros que tiveram suas casas queimadas por jagunços a serviço de grileiros, fazendeiros e sido despejados, quase sempre violentamente, por equipes judiciais; os que são presos, quase sempre arbitrariamente e até submetidos a torturas, como às vezes acontece no Mato Grosso e no sul do Pará; os que adoecem ou morrem especialmente crianças, após a expulsão, por falta de recursos; e até mesmo os que, lançados fora da terra, deslocam-se mais para dentro da mata, à procura de terras ainda não disputadas pelas grandes fazendas e empresas e ali sucumbem vitimados pela malária, como aconteceu há não muito tempo em Jaru, no Território de Rondônia, ou na Rodovia PA-100, no sul do Pará. (MARTINS, 1986, p. 106)

Trazendo alguns dados mais recentes para contribuir na reflexão sobre essa violência empregada nos conflitos na Amazônia Legal, Ferreira (2017) relata que no ano 
de 2014, dos conflitos por terra no Brasil, 43,4\% ocorreram nessa região. O autor acrescenta que

Trata-se, portanto, de uma região com altos índices no tocante aos conflitos por terra e, consequentemente, de violência contra os camponeses. A fronteira agrícola brasileira que cerca a Amazônia e também as demais regiões brasileiras foi gestada na Ditadura Militar, e atinge hodiernamente índices ascendentes ano após ano, envolvendo o desmatamento, a violência e a barbárie no campo. Mortes e perda de biodiversidade justificada e mascarada em nome da expansão do capital no campo brasileiro e da ganância por concentração de terras, rotuladas como o agronegócio moderno. Tão moderno em suas máquinas e tão arcaico em suas relações sociais. Madeira, grãos e terra manchadas de sangue de camponeses, indígenas, quilombolas, ribeirinhos, povos da floresta e tanto outros. (FERREIRA, 2017, p. 16-17)

Na faixa da Amazônia Legal de Mato Grosso, de acordo com dados da Comissão Pastoral da Terra ${ }^{12}$ desse estado (CPT/MT), 127 assassinatos no campo foram registrados entre os anos de 1985 e 2016, e nenhum dos mandantes foi preso. Além disso, esses dados apontam que foram registradas 70 ocorrências envolvendo 7.331 famílias, entre as quais "[...] 775 foram despejadas pelo Estado, 165 expulsas por pistoleiros e 272 sofreram ações de pistolagem" (CPT/MT, 2017, p. 67).

Neste sentido, a Comissão Pastoral da Terra do Estado de Mato Grosso denuncia que "[...] percebe-se que a história mato-grossense é marcada pela institucionalização estatal e empresarial da violência, exclusão e destruição da natureza. Tudo isso escondido sob o manto ideológico de progresso tecnológico, jurídico que empregam e matam a fome" (p. 66).

Entretanto, evidenciamos que nesse processo de luta contra o capital e seus interesses espalhados por todas as regiões do país, os povos e comunidades tradicionais constroem diversas maneiras para resistir. Ianni (2004C, p. 159, grifos do autor), ao relatar a resistência dos povos e comunidades tradicionais no período ditatorial afirma que,

\footnotetext{
${ }^{12}$ Organização de caráter ecumênico criada em 1975 por bispos da Igreja Católica, que tem como proposta assessorar os povos da terra e assalariados do campo na luta por terra, pela produção e por direitos.
} 
É só na aparência que o campesinato, o operário e o índio não lutam contra a ditadura militar. Na prática, estão lutando pela terra, a sindicalização, a proteção ao trabalho assalariado, o patrimônio cultural indígena, o crédito ao pequeno lavrador, o acesso ao mercado e outros objetivos econômicos e políticos. Combatem a grilagem, a jagunçagem e a superexploração do assalariado rural, as invasões das terras tribais, as prerrogativas econômicas e políticas de latifundiários e empresários junto ao aparelho estatal, a subserviência da burocracia pública aos interesses do capital monopolista, a aliança entre jagunços e policiais. Nas lutas por seus objetivos econômicos e políticos, combatem as bases agrárias da ditadura. O posseiro e o peão na Amazônia; o colono no Rio Grande do Sul e em Santa Catarina; o bóia-fria em São Paulo e no Paraná; o trabalhador de eito, cassaco e Corumbá em Pernambuco e outros Estados do Nordeste; os índios em muitas partes do Brasil: todos estão engajados em lutas sociais que envolvem a organização democrática das relações econômicas e políticas na sociedade brasileira.

A partir das ideias de Thompson (1998) e de Silva e Sato (2012), identificamos que existem as resistências explícitas, diretas ou abertas e aquelas implícitas, indiretas ou dissimuladas frente às ações de capitalistas do campo e da cidade, governos (municipais, estaduais e federais) etc. Faz parte do primeiro grupo de resistência às mobilizações em Brasília, nos estados e em diversos municípios do país, ocupações de fazendas, organização e mobilização para fechar rodovias, elaboração de documentos, inclusive de denúncias, a Produção Associada ${ }^{13}$ e agroecológica, a luta e mobilização pelos direitos legalmente conquistados, entre outros.

Thompson (1998), ao analisar os comportamentos culturais e costumeiros no século XVIII, destaca várias ações dos plebeus e das plebeias como formas de resistência frente às racionalizações e inovações da economia (disciplina de trabalho, cercamentos dos campos etc.) que os comerciantes, os empregadores e os governantes queriam impor. Entre as várias manifestações diretas de resistência citadas pelo autor, estavam a intercepção de carroças, a interdição do deslocamento de grãos, o bloqueio das estradas com o intuito de impedir a exportação de mercadorias, as ameaças de destruição de

\footnotetext{
${ }^{13}$ De acordo com Caetano e Neves (2014, p. 602), a Produção Associada é "[...] uma das estratégias de que os trabalhadores e trabalhadoras pertencentes aos setores populares lançam mão, visando a garantia da reprodução ampliada da vida através de práticas econômico-sociais e culturais que se diferenciam da racionalidade da economia capitalista"”."
} 
canais, a inspeção de estoques de grãos dos fazendeiros, a destruição e queima de moinhos a vapor devido ao aumento repentino no preço da farinha etc.

No segundo grupo de resistência, elencamos as lutas que vários povos e comunidades tradicionais travam para não serem "incorporados": a) o resgate de práticas culturais e costumeiras, por parte de diversos povos e comunidades tradicionais que foram expropriados delas, entre elas, daqueles povos indígenas considerados "ressurgidos" (AMORIM, 2003; 2010); b) a produção de alimentos e venda em feiras; c) ao aceitar um convite de reunião de um representante do poder (político, padre, diretor ou diretora escolar etc.) e negá-lo ao não comparecer; d) ao trocar seus produtos sem a utilização do dinheiro; e) a produção a partir de sementes crioulas e não por sementes transgênicas ou convencionais; f) ao manter a produção agroecológica; g) ao realizar fechamento de rodovias.

Desta forma, segundo Thompson (1998, p. 64),

\begin{abstract}
Numa sociedade de total dependência e clientelismo, encontra-se frequentemente a ameaça anônima, ou até o ato terrorista individual, no outro lado da moeda da deferência simulada. É exatamente numa sociedade rural, em que toda resistência aberta e identificada ao poder vigente pode resultar em retaliação imediata - perda da casa, emprego, arrendamento, se não vitimação pela lei - que tendemos a encontrar os atos obscuros: a carta anônima, o incêndio criminoso da lenha ou da casinha, o gado jarretado, o tiro ou tijolo pela janela, o portão fora dos gonzos, as árvores do pomar derrubadas, as comportas do lago dos peixes abertas à noite. $O$ mesmo homem que faz uma reverência ao fidalgo de dia - e que entra na história como exemplo de deferência pode à noite matar as suas ovelhas, roubar os seus faisões ou envenenar os seus cães.
\end{abstract}

Considerando que em alguns contextos não é possível manifestar resistência explícita, direta ou aberta, conforme exposto por Thompson (1998), já que é preciso manter a existência - comer, beber, dormir, vestir e "algumas coisas mais" (MARX; ENGELS, 2007, p. 33) - e, para isso, estabelecer relações com a sociedade, os povos e comunidades tradicionais expressam aquela resistência que é implícita, indireta ou dissimulada, como também já discorrido em parágrafos anteriores. 
Assim, a resistência dos povos e comunidades tradicionais se constrói em contraposição à presença violenta do modo de produção capitalista à produção de suas existências. Como é o caso comunidade quilombola Capão Verde (NEVES, 2013), da comunidade tradicional Imbê (SANTOS, 2013) e da comunidade quilombola Campina de Pedra (GUERINO, 2013), todas localizadas no município de Poconé, Estado de Mato Grosso.

Essas comunidades, baseadas na lógica da Produção Associada, resistem à lógica do modo de produção capitalista, pois possuem liberdade de morar e plantar no espaço que se deseja dentro da comunidade, se ajudam mutuamente, estabelecem forte vínculo e identidade com a terra, partilham mutuamente seus saberes construídos e transmitidos na experiência, compartilham os instrumentos de trabalho, fazem mutirões para limpeza, plantação e construção de casas e produzem para consumo imediato e para trocar o excedente por valores de uso (GUERINO, 2013; NEVES, 2013; SANTOS, 2013).

Os povos e comunidades tradicionais resistem para sobreviver física e identitariamente em seus territórios tradicionais, como é o caso do povo indígena Chiquitano (SILVA, 2015). Resistem para que haja a democratização dos meios de produção (NEVES, 2013; SANTOS, 2013; GUERINO, 2013), bem como para que haja a mudança da matriz energética, o desenvolvimento sustentável, a conservação e conhecimento da natureza, a demarcação dos territórios indígenas, o reconhecimento dos territórios quilombolas, a desconcentração e descentralização das terras e o protagonismo social (SILVA; SATO, 2010; SILVA, 2011; SILVA, 2012). Resistem pela luta.

De acordo com lanni (2004a, p. 251),

À medida que se desenvolve o capitalismo, a partir da indústria, comércio e banco, ou da cidade, os muitos núcleos de trabalhadores rurais e as muitas comunidades indígenas são induzidos a proletarizarem-se ou seguir adiante, em busca de outras terras. Muitos são os que resistem, lutam. Lutam para continuar em suas terras ou para reconquistá-las.

Enfim, luta-se pela terra-de-trabalho, pela terra que é vida, pela vida que é natureza, pela humanidade enquanto parte da natureza, que é a luta política pela 
preservação da produção da existência. Luta-se pela autonomia na produção, comercialização e consumo das mercadorias produzidas. Luta-se pela preservação do território e, portanto, também da identidade. Luta-se pela vida!

\section{Considerações finais}

Além de buscar alterar o modo e a organização da produção da vida imaterial (linguagem, religiosidade, costumes, tradições) dos povos e comunidades tradicionais, o modo de produção capitalista visa expropriar suas terras, sua força de trabalho, seus produtos para uma maior maximização do lucro. Tenta-se limitar a diversidade de produtos, negar a produção agroecológica, a importância da utilização de remédios naturais, ou seja, tenta-se expropriar a produção da vida imaterial e material.

Entre os projetos citados nesse texto, está o agronegócio, que tem territorializado o capital, visando à apropriação do campo ao seu favor. Por isso, a industrialização e a mercantilização dos recursos naturais essenciais à vida, tais como água e alimentos. Uma das consequências é a divisão entre a força de trabalho e os meios de produção, além do monopólio sobre a terra, o capital e os produtos.

O agronegócio traz em sua gênese a monocultura - de soja, algodão, milho, canade-açúcar, trigo, eucalipto, entre outros -; os impactos ecológicos, sociais, culturais e econômicos; o uso abusivo de agrotóxicos; a industrialização de fertilizantes e adubos; o oligopólio e a industrialização das sementes (convencionais e transgênicas); a homogeneidade; a insegurança alimentar; a fome etc.

O acesso à terra é indispensável ao capital, o qual acontece por meio da compra, da grilagem, do arrendamento, da desapropriação de assentados, posseiros e povos e comunidades tradicionais. É preciso ainda a concentração de terras, que é vista como mercadoria e meio de obtenção de lucro pelos capitalistas e como espaço físico que proporciona a continuação da existência material e imaterial pelos povos e comunidades tradicionais. 
Na tentativa de desapropriar e negar os povos e comunidades tradicionais do acesso à terra, ocorrem as tensões e os conflitos entre esses e os capitalistas. Do lado do capital, utilizam-se a força, a violência - física, psicológica, moral, cultural e simbólica -, a grilagem e a invasão das terras, a exploração da força de trabalho, isto é, a expulsão e a eliminação dos povos e comunidades tradicionais, pois são considerados entraves ao desenvolvimento brasileiro. Por seu lado, os povos e comunidades tradicionais existem e persistem resistindo no sentido de continuarem produzindo suas existências em contraposição aos valores e lógica do modo de produção capitalista, negando suprir as demandas do Mercado.

As resistências por parte dos povos e comunidades tradicionais podem ser explícitas, diretas ou abertas - mobilizações em Brasília, nos estados e em diversos municípios do país, ocupações de fazendas, elaboração de documentos, a Produção Associada e agroecológica, entre outras -, e/ou implícitas indiretas ou dissimuladas - as lutas que vários povos indígenas travam para não serem "incorporados"; o resgate de práticas culturais e costumeiras, por parte de diversos povos e comunidades tradicionais, a produção de alimentos e venda em feiras etc.

Eles e elas resistem com o intuito de manter a sobrevivência - física e identitária -, de alterar a matriz energética do país, preservar a natureza, demarcar os territórios indígenas, reconhecer os territórios quilombolas, desconcentrar e descentralizar as terras etc. Resistem em favor da terra, da natureza, da produção da existência baseada em uma lógica, específica e contraditória a do capital, da autonomia, enfim, da vida.

Apesar do modo de produção capitalista se apresentar enquanto hegemônico, os povos e comunidades tradicionais não se deixaram e não se deixam cooptar pelos imperativos do capital tanto na produção-circulação quanto na produção da vida imaterial. Dessa forma, terra, força de trabalho, meios de produção, produtos estão fora da esfera de seu domínio. Em momento de crise, um modo de produção da vida alternativo ao do capital é um perigo à própria reestruturação dos fundamentos e da conjuntura da sociedade capitalista, por isso, a necessidade de eliminá-lo. 


\section{Referências}

ALTIERI, Miguel. Agroecologia: bases científicas para uma agricultura sustentável. São Paulo: Expressão Popular, 2012.

AMIN, Samir; VERGOPOULOS, Kostas. A questão agrária e o capitalismo. Rio de Janeiro: Paz e Terra, 1977.

AMORIM, Siloé Soares de. Índios ressurgidos: a construção da auto-imagem os tumbalala - Os Kalankó, os Karuazu, os Catókinn e os Koiupanká. 2003, 301f. Dissertação (Mestrado em Multimeios)- Universidade Estadual de Campinas, Campinas, SP, 2003.

AMORIM, Siloé Soares de. Os Kalankó, Karuazu, Kaoipanká e Katokinn: resistência e ressurgência indígena no Alto Sertão alagoano. 2010, 431f. Tese (Doutorado em Antropologia Social)- Universidade Federal do Rio Grande do Sul, Porto Alegre, 2010.

ARESI, Cláudia. O território como suporte identitário para a cultura Kaingang. CAMPOTERRITÓRIO: revista de geografia agrária, v.3, n. 5, p. 264-279, fev. 2008. Disponível em: http://www.seer.ufu.br/index.php/campoterritorio/article/view/11840/6929. Acesso em 27 ago. 2017.

ARRIGHI, Giovanni. A ilusão do desenvolvimento. Rio de Janeiro: Vozes, 1997.

BRASIL. Decreto, $n^{\circ}$ 6.040, de 7 de fevereiro de 2007: Institui a Política Nacional de Desenvolvimento Sustentável dos Povos e Comunidades Tradicionais. Disponível em: http://www.planalto.gov.br/ccivil_03/_ato2007-2010/2007/decreto/d6040.htm. Acesso em: 21 mar. 2017.

CAETANO, Edson; NEVES, Camila Emanuella Pereira. Entre cheias e vazantes: trabalho, saberes e resistência em comunidades tradicionais da baixada cuiabana. Revista de Educação Pública, Cuiabá, v. 23, n. 53/2, p. 595-613, maio/ago., 2014. Disponível em: <http://periodicoscientificos.ufmt.br/index.php/educacaopublica/article/view/1756/1324>. Acesso em: 19 fev. 2016.

CARVALHO, Horácio Martins de. $O$ campesinato do século XXI: possibilidades do desenvolvimento do campesinato no Brasil. Rio de Janeiro: Vozes, 2005.

CARVALHO, Murilo. Sangue da terra: a luta armada no campo. 2 ed. São Paulo: Ed. Brasil Debates, 1980.

COMISSÃO PASTORAL DA TERRA - MATO GROSSO (CPT/MT). Os conflitos no Mato Grosso. In: COMISSÃO PASTORAL DA TERRA - MATO GROSSO. Atlas de conflitos na Amazônia. Goiânia: CPT; São Paulo: Entremares, 2017. p. 66-67. 
CRUZ, Valter do Carmo. Povos e comunidades tradicionais. In: CALDART, Roseli Salete; PEREIRA, Isabel Brasil; ALENTEJANO, Paulo; FRIGOTTO, Gaudêncio (Orgs.). Dicionário da educação do campo. Rio de Janeiro: Escola Politécnica de Saúde Joaquim Venâncio; São Paulo: Expressão Popular, 2012. p. 596-602.

DELGADO, Guilherme da Costa. Capital financeiro e agricultura na Brasil. São Paulo: Unicamp, 1985.

DIEGUES, Antonio Carlos et al. Os saberes tradicionais e a biodiversidade no Brasil. Brasília: Ministério do Meio Ambiente, dos Recursos Hídricos e da Amazônia Legal; São Paulo: USP, 2000.

FAO, IFAD, UNICEF, WFP and WHO. The State of Food Security and Nutrition in the World 2018. Building climate resilience for food security and nutrition. Rome, FAO, 2018. Disponível em: <http://www.fao.org/3/l9553EN/i9553en.pdf>. Acesso em: 14 set. 2018.

FERNANDES, Florestan. A revolução burguesa no Brasil: ensaio de interpretação sociológica. São Paulo: Globo, 2005.

FERREIRA, Gustavo Henrique Cepolini. Atlas da Amazônia Legal: uma construção metodológica, teórica e de luta! In: CPT. Atlas de conflitos na Amazônia. Goiânia: CPT; São Paulo: Entremares, 2017. p. 15-18.

GUERINO, Mariana de Fátima. O movimento dos saberes na produção da vida na comunidade quilombola Campina de Pedra. 2013, 140f. Dissertação (Mestrado em Educação)- Universidade Federal de Mato Grosso, Cuiabá, MT, 2013.

IANNI, Octavio. A luta pela terra: história social da terra e da luta pela terra numa área da Amazônia. Petrópolis, RJ: Vozes, 1978.

IANNI, Octavio. A questão agrária e as formas do Estado. In: IANNI, Octavio. Origens agrárias do Estado brasileiro. São Paulo: Brasiliense, 2004a. p. 241-255.

IANNI, Octavio. Ditadura e agricultura: o desenvolvimento do capitalismo na Amazônia 1964-1978. Rio de Janeiro: Civilização Brasileira, 1979.

IANNI, Octavio. Estado e capitalismo. São Paulo: Brasiliense, 2004b.

IANNI, Octavio. Lutas sociais no campo. In: IANNI, Octavio. Origens agrárias do Estado brasileiro. São Paulo: Brasiliense, 2004c. p. 155-159.

INSTITUTO BRASILEIRO DE GEOGRAFIA E ESTATISTICA (IBGE). Síntese de indicadores sociais: uma análise das condições de vida da população brasileira: 2017. Rio de Janeiro: IBGE, 2017. Disponível em: <https://biblioteca.ibge.gov.br/visualizacao/livros/liv101459.pdf>. Acesso em: 24 abr. 2018. 
KOSÍK, Karel. Dialética do Concreto. Rio de Janeiro: Paz e Terra, 2011. $9^{\text {a }}$ reimpressão.

KRENAK, A. Conferência "Estado, Capital e Territórios Tradicionais". In: POVOS e comunidades tradicionais: contribuições para outro desenvolvimento. Montes Claros: Unimontes, 2016.

LONDRES, Flávia. Agrotóxicos no Brasil: um guia para ação em defesa da vida. Rio de Janeiro: AS-PTA, 2011.

MANDEL, Ernest. A crise do capital: os fatos e sua interpretação marxista. São Paulo: Ensaio, 1990.

MANDEL, Ernest. O capitalismo Tardio. São Paulo: Abril cultural, 1982.

MARTINS, José de Souza. Capitalismo e tradicionalismo: estudos sobre a contradição da sociedade agrária no Brasil. São Paulo: Livraria Pioneira Editora, 1975.

MARTINS, José de Souza. Expropriação e violência: a questão política no campo. São Paulo: Editora Hucitec, 1982.

MARTINS, José de Souza. Os camponeses e a política no Brasil: as lutas sociais no campo e seu lugar no processo político. 3 ed. Petrópolis, RJ: Vozes, 1986.

MARTINS, José de Souza. O cativeiro da terra. São Paulo: Livraria Editora Ciências Humanas, 1981.

MARX, Karl. A guerra civil na França. Tradução Rubens Enderle. São Paulo: Boitempo, 2011.

MARX, Karl. O capital. A crítica a economia política. Livro I. Volume II. Rio de Janeiro: Civilização Brasileira, 1980.

MARX, Karl. O capital. Crítica da economia política. Livro I. Volume I. Rio de Janeiro: Editora Bertrand, 1988.

MARX, Karl; ENGELS, Friedrich. Feuerbach e história - rascunhos e anotações: do fim de novembro de 1845 a meados de abril de 1846. In: MARX, Karl; ENGELS, Friedrich (18181883). A ideologia alemã: crítica da mais recente filosofia alemã em seus representantes Feuerbach, B. Bauer e Stirner, e do socialismo alemão em seus diferentes profetas (18451846). Tradução Rubens Enderle, Nélio Schneider, Luciano Cavini Martorano. São Paulo: Boitempo, 2007. p. 29-81.

MOREIRA, Roberto José. Terra, poder e território. São Paulo: Expressão Popular, 2007. 
NEVES, Camila Emanuella Pereira. A produção associada em Capão Verde: entre bananas, saberes e utopias. Cuiabá: EdUFMT, 2013.

SAMPAIO JÚNIOR, Plínio de Arruda. Desenvolvimentismo e neodesenvolvimentismo: tragédia e farsa. Serviço Social e Sociedade, São Paulo, n. 112, p. 672-688, out./dez. 2012. Disponível em: <http://www.scielo.br/pdf/sssoc/n112/04.pdf>. Acesso em: 24 abr. 2018.

SANTOS, José Vicente Tavares dos. Matuchos - exclusão e luta: do Sul para a Amazônia. Rio de Janeiro: Vozes, 1993.

SANTOS, Lirian Keli dos. Trabalho, produção associada e produção de saberes na comunidade tradicional Imbê-MT. 2013, 185f. Dissertação (Mestrado em Educação)Universidade Federal de Mato Grosso, Cuiabá, MT, 2013.

SILVA, Adnilson de Almeida. Impactos socioculturais em populações indígenas de Rondônia: estudo da Nação Jupaú. 2007, 273f. Dissertação (Mestrado em Geografia)Fundação Universidade Federal de Rondônia, Porto Velho, 2007.

SILVA, Marília de Almeida. Por uma cultura latino-américa da produção livre e associada: o povo Chiquitano e a experiência indígena no Brasil. 2015, 187f. Dissertação (Mestrado em Educação)- Universidade Federal de Mato Grosso, Cuiabá, MT, 2015.

SILVA, Michelle Jaber da; SATO, Michèle Tomoko. Territórios em tensão: o mapeamento dos conflitos socioambientais do estado de Mato Grosso - Brasil. Ambiente \& Sociedade, São Paulo, v. XV, n. 1, p. 1 -28, jan.-abr. 2012. Disponível em: <http://www.scielo.br/pdf/asoc/v15n1/02.pdf>. Acesso em: 23 out. 2017.

SILVA, Michelle Tatiane Jaber da O mapeamento dos conflitos socioambientais de Mato Grosso: denunciando injustiças ambientais e anunciando táticas de resistência. 2012, 253f. Tese (Doutorado em Ecologia e Recursos Naturais)- Universidade Federal de São Carlos, São Carlos, SP, 2012.

SILVA, Regina Aparecida da. Do invisível ao visível: o mapeamento dos grupos sociais do estado do Mato Grosso - Brasil. 2011, 222f. Tese (Doutorado em Ecologia e Recursos Naturais)- Universidade Federal de São Carlos, São Carlos, SP, 2011.

SILVA, Regina; SATO, Michèle. Territórios e identidades: mapeamento dos grupos sociais do estado do Mato Grosso - Brasil. Ambiente \& Sociedade, Campinas, v. XIII, n. 2, p. 261281, jul.-dez. 2010. Disponível em: <http://www.scielo.br/pdf/asoc/v13n2/v13n2a04.pdf z. Acesso em: 23 out. 2017.

SIMIONE, Roberta Moraes. Território de Mata Cavalo: Identidades em movimento na Educação Ambiental. 2008, 142f. Dissertação (Mestrado em Educação)- Universidade Federal de Mato Grosso, Cuiabá, 2008. 
THOMPSON, Edward Palmer. Costumes em comum: estudos sobre a cultura popular tradicional. São Paulo: Companhia das Letras, 1998.

ZIEGLER, Jean. Destruição em massa: geopolítica da fome. São Paulo: Cortez, 2013.

Recebido em: 08/12/2017

Aprovado 23/04/2018

Universidade do Estado de Santa Catarina - UDESC

Centro de Ciências Humanas e da Educação - FAED

Revista PerCursos

Volume 19 - Número 40 - Ano 2018 revistapercursos@gmail.com 